Kalmar, Sweden, November 24-26, 2014

\title{
ENHANCEMENT OF AMPEROMETRIC RESPONSE OF GLUCOSE BIOSENSOR BY ELECTRODEPOSITION OF SILVER NANOPARTICLES ONTO CHITOSAN-MODIFIED ELECTRODE
}

\author{
Hossein Zare \\ Ghasem Najafpour \\ Mohsen Jahanshahi \\ Mostafa Rahimnejad
} Mohsen Rezvani Biotechnology Research Lab., Faculty of Chemical Engineering, Noshirvani University of Technology, Babol, Iran

\begin{abstract}
A highly sensitive biosensor based on silver nanoparticles (AgNPs) was fabricated for glucose detection in aqueous phase. Firstly, a platinum (Pt) electrode was modified with the mixture of glucose oxidase and chitosan. AgNPs were electrodeposited into the modified electrode by single pulse potentiostatic method at $-0.4 \mathrm{~V}$. The electrochemical performance of the modified electrode was evaluated by cyclic voltammetry and amperometry. The fabricated biosensor had a high sensitivity of $58.6 \mu \mathrm{A} \mathrm{mM}{ }^{-1} \mathrm{~cm}^{-2}$ and detection limit of $4.4 \mu \mathrm{M}$ glucose at a signal to noise ratio of 3. In addition, the biosensor showed a short response time less than $5 \mathrm{~s}$ and a wide linear range of $0.05-11.5 \mathrm{mM}$. The apparent Michaelis-Menten constant $\left(\mathrm{K}_{\mathrm{M}}\right)$ was found to be 9.14 $\mathrm{mM}$. In addition, thermal stability and anti-interference ability of the biosensor were investigated. The results demonstrated that AgNPs enhanced the analytical performance of the biosensor.
\end{abstract}

\section{KEYWORDS}

Biosensor; Silver nanoparticles; Chitosan; Glucose oxidase; Electrodeposition.

\section{INTRODUCTION}

Over the last decades, electrochemical biosensors have attracted considerable attention because of their simple procedure and also accurate and fast response [1, 2]. These advantageous features make biosensors applicable in food industry, monitoring environmental issues and especially in 


\section{Linnaeus ECO-TECH`14}

\section{Kalmar, Sweden, November 24-26, 2014}

health care and medical diagnostics $[3,4]$. Glucose analysis is one of the healthcare measurements which is essential for diabetic patients [5].

Enzymes have been widely used in bioanalytical assays due to their high selectivity, rapid and specific responses to substrates. For glucose detection, glucose oxidase (GOx) with high activity in a wide range of temperature and $\mathrm{pH}$ is used that is found in various fungal sources. GOx is a glycoprotein consisting of two identical polypeptide chains which covalently joined together by disulfide bonds [5, 6]. GOx catalyzes the oxidation of glucose to gluconolactone (which can be hydrolyzed to gluconic acid) and $\mathrm{H}_{2} \mathrm{O}_{2}$ in the presence of oxygen. Monitoring of electrochemical changes resulted from the enzymatic reaction and produced $\mathrm{H}_{2} \mathrm{O}_{2}$ are useful for detection of glucose $[2,7]$.

The various techniques based on physical (adsorption, entrapment, encapsulation) and chemical (cross-linking, covalent binding) methods are commonly used for enzyme immobilization [8-10]. Entrapment within porous matrices is an effective method for immobilization of enzyme on the surface of electrode [11]. Chitosan (CHIT) is a polysaccharide derived by deacetylation of chitin which is found in fungal cell walls and the exoskeleton of arthropods including insects, arachnids and crustaceans (lobsters, crabs and shrimps) [12, 13]. Increasingly over the last decade, CHIT has been used for enzyme immobilization in biosensors because it provides a biocompatible environment for enzyme, has no inhibitory effect on the enzyme activity and maintains enzymatic activity $[9,14]$.

In recent years, Metallic nanoparticles such as Ag, Pt, gold, and copper have been widely used for fabrication of biosensors because of unique electrical and catalytic properties [15, 16]. Silver has highest conductivity among the metals and is one of the most interesting nanoparticles used in biosensors $[17,18]$. Electron transfer between the immobilized enzyme and the electrode surface is one the most effective parameters in biosensors. Addition of AgNPs into the enzyme and support can effectively promote electron transfer and enhance analytical performance of biosensor $[19,20]$.

In this work an electrochemical biosensor was fabricated with the aid of CHIT and AgNPs for determination of glucose. AgNPs were electrodeposited into the CHIT-modified electrode using single pulse potentiostatic method. The performance of the biosensor was evaluated with cyclic voltammetric and amperometric experiments. The activation energy and apparent MichaelisMenten constant were determined. The influence of two interfering species on the biosensor response was studied. Also the thermal stability of the biosensor was investigated and the optimum temperature of the biosensor was defined.

\section{MATERIAL AND METHODS}

\subsection{Chemicals}

Glucose oxidase (GOx) (E.C.1.1.3.4, type X-S, $153100 \mathrm{Ug}^{-1}$ ) from Aspergillus niger, chitosan (CHIT) (85\% deacetylated) and silver nitrate $\left(\mathrm{AgNO}_{3}\right)$ were supplied by Sigma-Aldrich (USA). All other chemicals were purchased from Merck (Germany). A 0.1 M phosphate buffer (PB) (pH 7) solution was prepared using $\mathrm{K}_{2} \mathrm{HPO}_{4}$ and $\mathrm{KH}_{2} \mathrm{PO}_{4}$. $\mathrm{KCl}(0.1 \mathrm{M})$ was added to $\mathrm{PB}$ solution to prevent charged electroactive species from migrating in the electric field gradient. The $\mathrm{pH}$ of the 


\title{
Linnaeus ECO-TECH`14
}

\author{
Kalmar, Sweden, November 24-26, 2014
}

supporting electrolyte was adjusted to 7.0 by $\mathrm{KOH}$. Glucose stock solution $(0.1 \mathrm{M})$ was prepared and stored at room temperature for $24 \mathrm{~h}$ to ensure mutarotation equilibrium. CHIT solution was prepared by dissolving CHIT powder in $1 \mathrm{wt} \%$ acetic acid solution and stirred at room temperature for $30 \mathrm{~min}$. The CHIT and glucose stock solution were stored at $4{ }^{\circ} \mathrm{C}$ when not in use.

\subsection{Electrochemical measurements}

All electrochemical experiments were conducted using a potentiostat/galvanostat (Ivium, A08085, Netherlands). A conventional three-electrode system was employed with modified platinum (Pt) as the working electrode (2 mm diameter), a Pt wire as the auxiliary electrode and $\mathrm{Ag} / \mathrm{AgCl}$ as the reference electrode. All electrodes were obtained from Azar-Electrode (Iran). Electrochemical measurements were conducted in an electrochemical cell containing $10 \mathrm{~mL}$ supporting electrolyte. All potentials were reported versus Ag/AgCl. A heater stirrer (Velp, Scientifica, Italy) equipped with thermoregulator was used for adjusting temperature of the electrolyte. Amperometric measurements were performed at $150 \mathrm{rpm}$ using a stirring bar to ensure convective transport.

\subsection{Electrode preparation}

Prior to each experiment, the Pt working electrode was boiled in $6 \mathrm{M} \mathrm{HNO}_{3}$ and polished using $0.05 \mu \mathrm{m}$ alumina slurry, and then washed with double distilled water. The electrode was ultrasonicated in double distilled water and allowed to dry at room temperature. Entrapment method was used to immobilize GOx on the surface of electrode. Firstly, $10 \mu \mathrm{L}$ of $5 \mathrm{mg} \mathrm{mL}^{-1}$ GOx and $0.4 \mathrm{wt} \%$ CHIT solution was dropped onto the Pt electrode surface and dried in air for 6 h. In order to deposit AgNPs into the CHIT-GOx/Pt electrode, single pulse potentiostatic deposition was applied at $25{ }^{\circ} \mathrm{C}$ and a potential of $-0.4 \mathrm{~V}$ versus $\mathrm{Ag} / \mathrm{AgCl}$ for $40 \mathrm{~s}$. Electrodeposition was performed by dipping the electrode in an electrolyte solution containing $0.5 \mathrm{mM} \mathrm{AgNO}, 0.1 \mathrm{M} \mathrm{KNO}_{3}$ and $0.2 \mathrm{mM}$ sodium citrate $\left(\mathrm{C}_{6} \mathrm{H}_{5} \mathrm{Na}_{3} \mathrm{O}_{7}\right)$. After that the electrode was rinsed with double distilled water, $5 \mu \mathrm{L}$ of nafion solution $(0.5 \mathrm{wt} \%)$ was coated on the surface of modified electrode and dried in air for $12 \mathrm{~h}$. The modified electrode was maintained at $4{ }^{\circ} \mathrm{C}$ in a dry state when not in use.

\section{RESULTS AND DISCUSSION}

\subsection{Cyclic voltammetry}

Biosensor response to glucose was evaluated by cyclic voltammetry at the modified electrode. Cyclic voltammetric experiments were performed in the absence and presence of glucose in 0.1 M PB solution at a scan rate of $100 \mathrm{mVs}^{-1}$ with applied potential 0.2-1.0 V. The cyclic voltammograms (CVs) of the modified electrode at different glucose concentrations from 1.96 to $12.28 \mathrm{mM}$ is shown in Figure 1. It can be seen the obvious peak currents were obtained in the presence of glucose which indicated that the fabricated biosensor would be able to clearly detect glucose substrate. The results showed that glucose was oxidized on the surface of modified electrode and as a result the current response proportional to the concentration of glucose was produced. 
Linnaeus ECO-TECH 14

Kalmar, Sweden, November 24-26, 2014

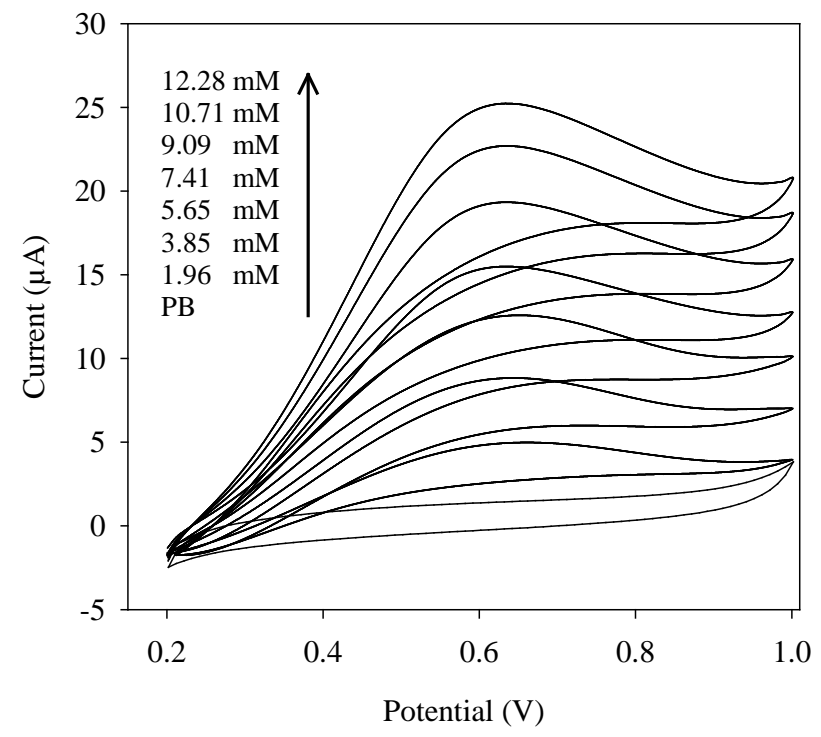

Figure 1. CVs of the fabricated biosensor at glucose concentrations of 1.96-12.28 $\mathrm{mM}$ in $0.1 \mathrm{M}$ $P B$ solution at a scan rate of $100 \mathrm{mVs}^{-1}$.

\subsection{Electroactive surface area of the biosensor}

Cyclic voltammetric experiment was carried out for the fabricated biosensor in $10 \mathrm{~mL}$ supporting electrolyte $(1 \mathrm{M} \mathrm{KCl})$ containing a probe redox $\left(5 \mathrm{mM} \mathrm{K}_{3}\left[\mathrm{Fe}(\mathrm{CN})_{6}\right]\right)$. Figure 2a shows the CVs of the modified electrode with applied potential from -0.3 to $0.85 \mathrm{~V}$ at scan rates of 10-50 $\mathrm{mVs}^{-1}$. The electroactive surface area of the modified electrode can be determined by RandlesSevcik equation which is applicable for reversible electrochemical reactions [15]:

$i_{p}=0.4463\left(\frac{F^{3}}{R T}\right)^{\frac{1}{2}} N^{\frac{3}{2}} A D^{\frac{1}{2}} C \times v^{\frac{1}{2}}$

where $i_{\mathrm{p}}(A)$ is the peak current of the $\mathrm{CV}, A\left(\mathrm{~cm}^{2}\right)$ is the electroactive surface area of the electrode, $N$ is the number of electrons transferred in redox process, $\left.C(\mathrm{~mol} \mathrm{~cm})^{-3}\right)$ is the concentration of redox probe, $D\left(\mathrm{~cm}^{2} \mathrm{~s}^{-1}\right)$ is the diffusion coefficient of redox probe $\left(\mathrm{K}_{3}\left[\mathrm{Fe}(\mathrm{CN})_{6}\right]\right)$ in supporting solution $(\mathrm{KCl}), v\left(\mathrm{~V} \mathrm{~s}^{-1}\right)$ is the scan rate, and $R, T$ and $F$ are the universal gas constant, the temperature in Kelvin and Faraday's constant, respectively.

The plot of peak current versus the square root of scan rate was fitted linearly (Figure 2b), which confirmed that the electron transfer of redox probe with modified electrode was diffusion controlled process [21]. By considering that $N$ for this redox reaction is equal to $1, D$ for $5 \mathrm{mM}$ $\mathrm{K}_{3}\left[\mathrm{Fe}(\mathrm{CN})_{6}\right]$ in $1 \mathrm{M} \mathrm{KCl}$ solution is $7.60 \times 10^{-6} \mathrm{~cm}^{2} \mathrm{~s}^{-1}$ [22], and from the slope of the linear Randles- Sevcik plot, the electroactive surface area of the modified electrode was calculated to be $2.03 \times 10^{-2} \mathrm{~cm}^{2}$. 
Linnaeus ECO-TECH 14

Kalmar, Sweden, November 24-26, 2014
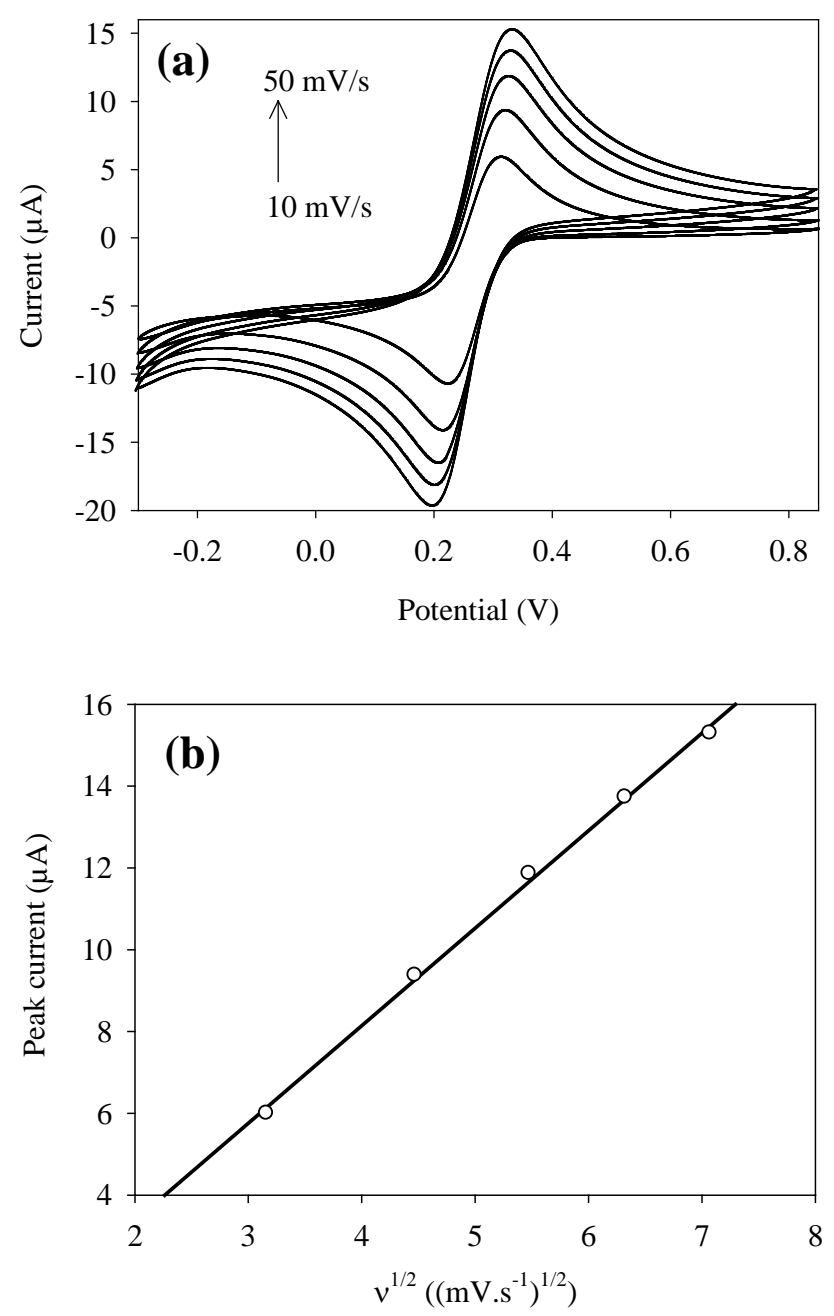

Figure 2. a) CVs of the biosensor at different scan rates of $10-50 \mathrm{mVs}^{-1}$ in $1 \mathrm{M} \mathrm{KCl}$ solution containing $5 \mathrm{mM} \mathrm{K}_{3}\left[\mathrm{Fe}(\mathrm{CN})_{6}\right]$. b) The plot of peak current versus the square root of scan rate.

\subsection{Biosensor performance}

Amperometric experiment was performed in the electrochemical cell containing $10 \mathrm{~mL}$ supporting electrolyte solution (0.1 M PB) with an applied potential of $+0.65 \mathrm{~V}$ at $25 \pm 0.2{ }^{\circ} \mathrm{C}$. After that the background current was reached to a steady state condition, the aliquots of glucose stock solution were added into the supporting electrolyte to make different glucose concentrations.

The current response as a function of glucose concentration is plotted in Figure 3a. A wide linear range of $0.05-11.5 \mathrm{mM}$ glucose concentration was obtained with correlation coefficient of 0.99 . The fabricated biosensor showed an excellent performance for glucose detection with a short response time of $5 \mathrm{~s}$, high sensitivity of $58.6 \mu \mathrm{A} \mathrm{mM} \mathrm{mm}^{-1}$ and detection limit of $4.4 \mu \mathrm{M}$ glucose at a signal to noise ratio of 3 . 
Linnaeus ECO-TECH 14

Kalmar, Sweden, November 24-26, 2014
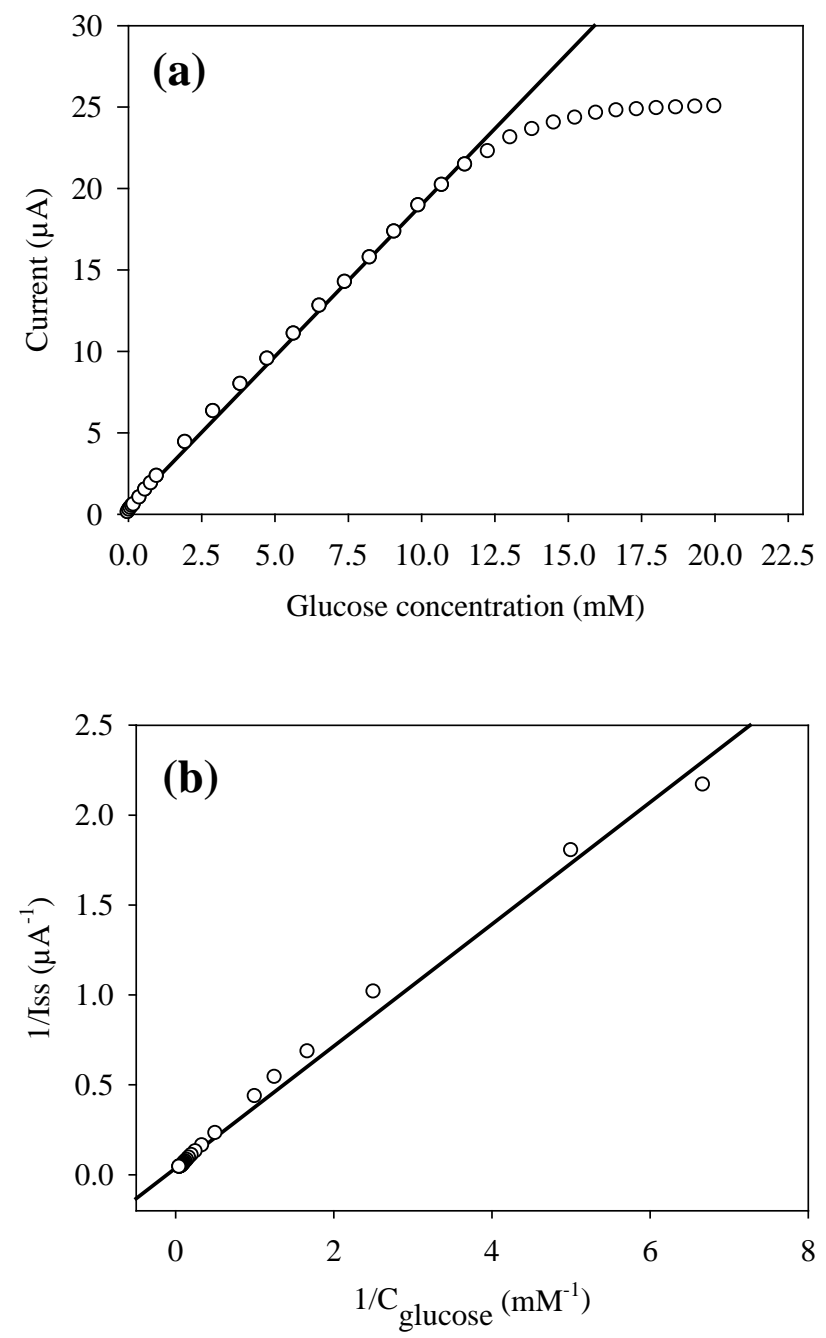

Figure 3. a) The current response as a function of glucose concentration, $b$ ) the plot of $1 / I_{\mathrm{sS}}$ versus $1 / C_{\text {glucose }}$ for determination of apparent Michaelis-Menten constant.

The electrochemical version of Lineweaver-Burk equation was employed to study the enzymesubstrate kinetic of the fabricated biosensor [23]:

$\frac{1}{I_{s s}}=\frac{1}{I_{\max }}+\frac{K_{M}}{I_{\max }} \frac{1}{C}$

where $I_{S S}$ is the steady state current response for each concentration of analyte, $I_{\max }$ is the maximum current response under saturated analyte condition, $\mathrm{C}$ is the analyte concentration in the supporting electrolyte solution and $\mathrm{K}_{\mathrm{M}}$ is the apparent Michaelis-Menten constant. The reciprocal of steady state current response versus the reciprocal of glucose concentration was plotted in the Figure 3b. From the slope and intercept of the Lineweaver-Burk plot, the $\mathrm{K}_{\mathrm{M}}$ value was determined to be $9.14 \mathrm{mM}$. The low value of $\mathrm{K}_{\mathrm{M}}$ indicated that CHIT and AgSNp assisted immobilized GOx to retain high enzymatic activity; therefore the fabricated biosensor showed a high affinity to glucose. 


\section{Linnaeus ECO-TECH` 14}

Kalmar, Sweden, November 24-26, 2014

\subsection{Effect of temperature}

The effect of temperature on the fabricated biosensor was studied in the temperature range 5 -75 ${ }^{\circ} \mathrm{C}$. The biosensor response to $5.6 \mathrm{mM}$ glucose solution versus the temperature is shown in Figure 4a. The current response showed an increase with increasing the temperature and reached to maximum value at $50^{\circ} \mathrm{C}$. At temperature higher than $50{ }^{\circ} \mathrm{C}$, the current response dramatically decreased due to enzyme denaturation. The obtained optimum temperature value for the fabricated biosensor was higher than those reported in the literature [24-26].

The Arrhenius equation ( $\mathrm{i}=\mathrm{i}_{0} \exp \left(-\mathrm{E}_{\mathrm{a}} / \mathrm{RT}\right)$ ) was employed to study the relationship between current response and temperature. The plot of $\ln i$ versus $10^{3} / \mathrm{T}$ was depicted in the Figure $4 \mathrm{~b}$. From the slope of the linear region of Arrhenius plot, the activation energy was determined to be $23.45 \mathrm{~kJ} \mathrm{~mol}^{-1}$ which is in accordance with other glucose biosensors reported in the literature $\left(22.4-50 \mathrm{~kJ} \mathrm{~mol}^{-1}\right)[7,27]$.
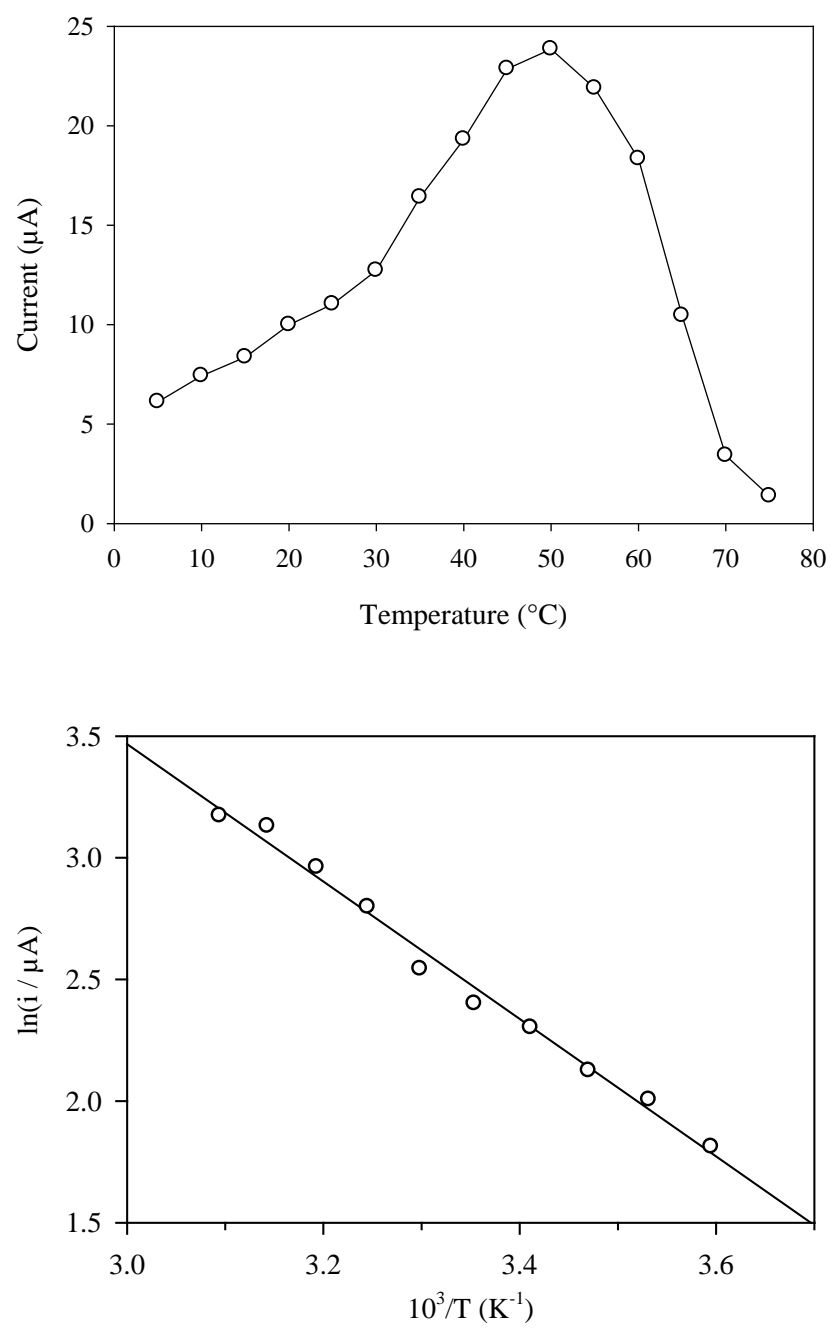

Figure 4. a) The influence of temperature on the biosensor current response to $5.6 \mathrm{mM}, \mathrm{b}$ ) Arrhenius plot for determination of activation energy, plot of In i versus $10^{3} / \mathrm{T}$ ). 


\subsection{Interference analysis}

Uric acid (UA) and ascorbic acid (AA) are common electroactive species which have undesired effect on the accuracy of glucose detection. In human blood, the concentration range of UA is 2.5-8.0 $\mathrm{mg} \mathrm{dL}^{-1}$ [28] (1 $\mathrm{mg} \mathrm{dL}^{-1}$ of UA equivalent to $\left.59.48 \mu \mathrm{M}\right)$. The upper level of AA in blood is about $1.3 \mathrm{mg} \mathrm{dL}^{-1}$ [29] $\left(1 \mathrm{mg} \mathrm{dL}^{-1}\right.$ of AA equivalent to $\left.56.78 \mu \mathrm{M}\right)$.

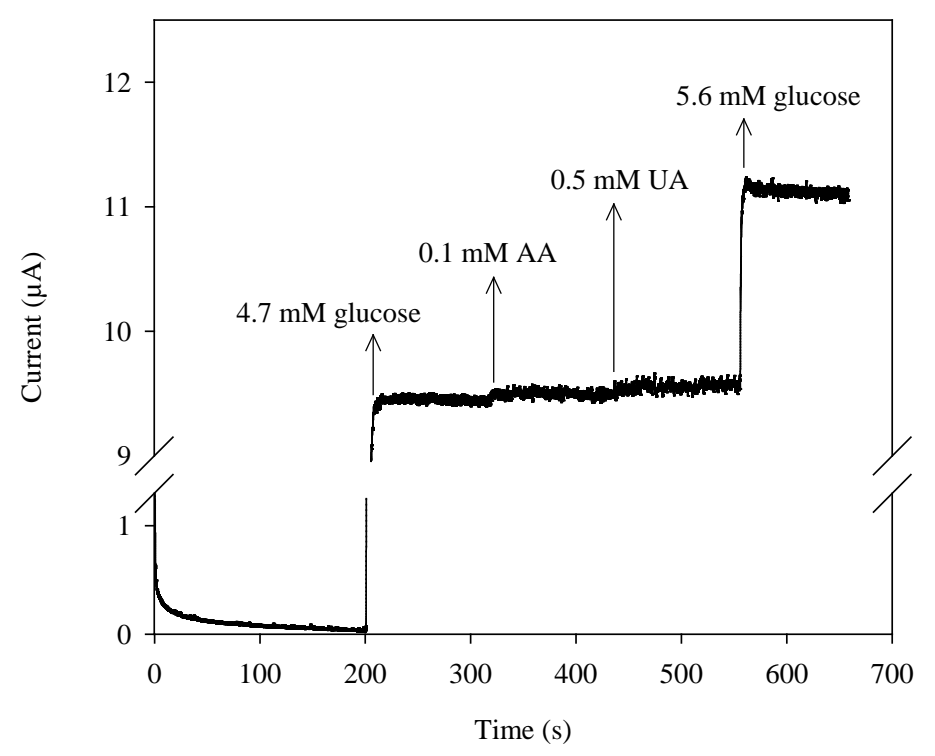

Figure 5. The effect of interfering species ( $0.1 \mathrm{mM} A A$ and $0.5 \mathrm{mM} \mathrm{UA})$ on the response of biosensor at $0.65 \mathrm{~V}$.

In this work, the influence of these two electroactive interferents on the amperometric response was investigated. For this purpose, a $0.1 \mathrm{mM} \mathrm{AA}$ and $0.5 \mathrm{mM}$ UA were consecutively added into $4.7 \mathrm{mM}$ glucose solution. In order to obtain a proper response to final glucose concentration of $5.6 \mathrm{mM}$, a $0.9 \mathrm{mM}$ glucose was added to the primary solution as discussed above. Figure 5 demonstrates the current responses to AA $(0.1 \mathrm{mM})$ and UA $(0.5 \mathrm{mM})$ were negligible (in compare to reference state, $4.7 \mathrm{mM}$ glucose). The current response to $5.6 \mathrm{mM}$ glucose was 11.25 $\mu \mathrm{A}$, which shows a slight increase $(1.8 \%)$ in compare to steady state current response $(11.05 \mu \mathrm{A})$ through amperometric measurement. According to obtained results, the fabricated biosensor showed a good anti-interference ability.

\section{CONCLUSIONS}

In present work a highly sensitive glucose biosensor was fabricated based on AgNPs. Gox was entrapped into CHIT and immobilized on the surface of Pt electrode. AgNPs were deposited into the CHIT-GOx modified electrode via electrodeposition method. The electroactive surface area of the modified electrode was calculated to be $2.03 \times 10^{-2} \mathrm{~cm}^{2}$. Based the obtained result, AgNPs greatly enhanced the electron transfer between immobilized enzyme and the Pt electrode. The low apparent Michaelis-Menten of $9.14 \mathrm{mM}$ indicated that CHIT provided biocompatible environment for immobilized GOx and assisted the enzyme to retain high enzymatic activity. Also the biosensor showed a good anti-interference ability which indicates CHIT and nafion 


\section{Linnaeus ECO-TECH`14}

\section{Kalmar, Sweden, November 24-26, 2014}

prevented interfering species (AA and UA) from diffusing through the modified electrode. Overall, the fabricated biosensor showed high analytical performance for glucose detection.

\section{ACKNOWLEDGMENTS}

The authors wish to acknowledge Biotechnology Research Center, Noshirvani University of Technology, Babol, Iran for the facilities provided to accomplish present research.

\section{REFERENCES}

[1] Wang, J., 2008. Electrochemical glucose biosensors. Chemical reviews 108(2), 814-825.

[2] Zhang, Y., Liu, Y., Chu, Z., Shi, L., Jin, W., 2012. Amperometric glucose biosensor based on direct assembly of Prussian Blue film with ionic liquid-chitosan matrix assisted enzyme immobilization. Sensors and Actuators B: Chemical 176, 978-984.

[3] Bai, Y., Yang, H., Yang, W., Li, Y., Sun, C., 2007. Gold nanoparticles-mesoporous silica composite used as an enzyme immobilization matrix for amperometric glucose biosensor construction. Sensors and Actuators B: Chemical 124(1), 179-186.

[4] Patel, P., 2002. (Bio) sensors for measurement of analytes implicated in food safety: a review. TRAC Trends in Analytical Chemistry 21(2), 96-115.

[5] Wang, J., 2001. Glucose biosensors: 40 years of advances and challenges. Electroanalysis 13(12), 983-988.

[6] Bankar, S.B., Bule, M.V., Singhal, R.S., Ananthanarayan, L., 2009. Glucose oxidase-an overview. Biotechnology advances 27(4), 489-501.

[7] Yu, J., Yu, D., Zhao, T., Zeng, B., 2008. Development of amperometric glucose biosensor through immobilizing enzyme in a Pt nanoparticles/mesoporous carbon matrix. Talanta 74(5), 1586-1591.

[8] Bourdillon, C., Laval, J.M., Thomas, D., 1986. Enzymatic electrocatalysis: controlled potential electrolysis and cosubstrate regeneration with immobilized enzyme modified electrode. Journal of the Electrochemical Society 133(4), 706-711.

[9] Krajewska, B., 2004. Application of chitin-and chitosan-based materials for enzyme immobilizations: a review. Enzyme and microbial technology 35(2), 126-139.

[10] Olea, D., Viratelle, O., Faure, C., 2008. Polypyrrole-glucose oxidase biosensor: Effect of enzyme encapsulation in multilamellar vesicles on analytical properties. Biosensors and Bioelectronics 23(6), 788-794.

[11] Norouzi, P., Pirali-Hamedani, M., Ganjali, M., Faridbod, F., 2010. A novel acetylcholinesterase biosensor based on chitosan-gold nanoparticles film for determination of monocrotophos using FFT continuous cyclic voltammetry. International Journal of Electrochemal Science 5, 1434-1446.

[12] Sheng, Q., Luo, K., Li, L., Zheng, J., 2009. Direct electrochemistry of glucose oxidase immobilized on $\mathrm{NdPO}_{4}$ nanoparticles/chitosan composite film on glassy carbon electrodes and its biosensing application. Bioelectrochemistry 74(2), 246-253.

[13] Yi, H., Wu, L.-Q., Bentley, W.E., Ghodssi, R., Rubloff, G.W., Culver, J.N., Payne, G.F., 2005. Biofabrication with chitosan. Biomacromolecules 6(6), 2881-2894.

[14] Tan, Y., Deng, W., Chen, C., Xie, Q., Lei, L., Li, Y., Fang, Z., Ma, M., Chen, J., Yao, S., 2010. Immobilization of enzymes at high load/activity by aqueous electrodeposition of enzyme-tethered chitosan for highly sensitive amperometric biosensing. Biosensors and Bioelectronics 25(12), 2644-2650. 


\section{Linnaeus ECO-TECH`14}

\section{Kalmar, Sweden, November 24-26, 2014}

[15] Kang, X., Mai, Z., Zou, X., Cai, P., Mo, J., 2007. A novel glucose biosensor based on immobilization of glucose oxidase in chitosan on a glassy carbon electrode modified with gold-platinum alloy nanoparticles/multiwall carbon nanotubes. Analytical Biochemistry 369(1), 71-79.

[16] Lu, L.-M., Zhang, L., Qu, F.-L., Lu, H.-X., Zhang, X.-B., Wu, Z.-S., Huan, S.-Y., Wang, Q.-A., Shen, G.-L., Yu, R.-Q., 2009. A nano-Ni based ultrasensitive nonenzymatic electrochemical sensor for glucose: Enhancing sensitivity through a nanowire array strategy. Biosensors and Bioelectronics 25(1), 218-223.

[17] Azariah, J.C.R., Saravanan, P., Raj, C.M., Rahamathullah, A., Veeramani, T., Singh, R.V., 2013. Thin Film Fabrication And Characterization Of Inkjet Printed Nano Silver (AG) Interconnects. International Journal of Engineering 2(4), 1015-1019.

[18] Rad, A.S., Jahanshahi, M., Ardjmand, M., Safekordi, A.-A., 2012. Hydrogen Peroxide Biosensor Based on Enzymatic Modification of Electrode Using Deposited Silver Nano Layer. International Journal of Electrochemical Science 7(3), 2623-2632.

[19] Gan, X., Liu, T., Zhong, J., Liu, X., Li, G., 2004. Effect of silver nanoparticles on the electron transfer reactivity and the catalytic activity of myoglobin. ChemBioChem 5(12), 1686-1691.

[20] Ren, X., Meng, X., Chen, D., Tang, F., Jiao, J., 2005. Using silver nanoparticle to enhance current response of biosensor. Biosensors and Bioelectronics 21(3), 433-437.

[21] Baranski, A.S., Krogulec, T., Nelson, L.J., Norouzi, P., 1998. High-frequency impedance spectroscopy of platinum ultramicroelectrodes in flowing solutions. Analytical Chemistry 70(14), 2895-2901.

[22] Guo, M., Hong, H., Tang, X., Fang, H., Xu, X., 2012. Ultrasonic electrodeposition of platinum nanoflowers and their application in nonenzymatic glucose sensors. Electrochimica Acta 63, 1-8.

[23] Wang, Y., Ma, X., Wen, Y., Zheng, Y., Duan, G., Zhang, Z., Yang, H., 2010. Phytic acidbased layer-by-layer assembly for fabrication of mesoporous gold film and its biosensor application. Journal of the Electrochemical Society 157(1), K5-K9.

[24] Gülce, H., Özyörük, H., Çelebi, S.S., Yildiz, A., 1995. Amperometric enzyme electrode for aerobic glucose monitoring prepared by glucose oxidase immobilized in poly (vinylferrocenium). Journal of Electroanalytical Chemistry 394(1), 63-70.

[25] Li, T., Yao, Z., Ding, L., 2004. Development of an amperometric biosensor based on glucose oxidase immobilized through silica sol-gel film onto Prussian Blue modified electrode. Sensors and Actuators B: Chemical 101(1), 155-160.

[26] Rubio-Retama, J., López-Cabarcos, E., López-Ruiz, B., 2005. High stability amperometric biosensor based on enzyme entrapment in microgels. Talanta 68(1), 99107.

[27] Poyard, S., Jaffrezic-Renault, N., Martelet, C., Cosnier, S., Labbe, P., 1998. Optimization of an inorganic/bio-organic matrix for the development of new glucose biosensor membranes. Analytica Chimica Acta 364(1), 165-172.

[28] Shin, J.Y., Lee, H.R., Shim, J.Y., 2012. Significance of high-normal serum uric acid level as a risk factor for arterial stiffness in healthy Korean men. Vascular Medicine 17(1), 3743.

[29] VanderJagt, D.J., Garry, P.J., Bhagavan, H.N., 1987. Ascorbic acid intake and plasma levels in healthy elderly people. The American journal of clinical nutrition 46(2), 290294. 